\title{
Spontaneous Intracystic Hemorrhage in an Adult with Cerebellopontine Angle Arachnoid Cyst and Management: A Case Report
}

\author{
Joel Passer, MD, Anand Kaul, MD* and Rami O Almefty, MD \\ Department of Neurosurgery, Temple University Hospital, Philadelphia, USA
}

*Corresponding author: Anand Kaul, MD, Department of Neurosurgery, Temple University Hospital, 3401 N Broad Street, Suite C540, Philadelphia, Pennsylvania 19140, USA

\begin{abstract}
Arachnoid cysts are common findings on neuroimaging and account for approximately $1 \%$ of all intracranial lesions. The cerebellopontine angle is the second most common location. When arachnoid cysts become symptomatic due to cyst growth, or rarely, cyst rupture, they create mass effect on adjacent neurovascular structures and may require neurosurgical management. This involves a posterior fossa decompression and cyst fenestration with or without cyst fluid diversion. We present a case of a 40 -year-old male who presented with a cerebellopontine angle arachnoid cyst with symptomatic spontaneous intracystic hemorrhage successfully managed conservatively, as well as a review of the literature.
\end{abstract}

\section{Keywords}

Arachnoid cyst, Cerebellopontine angle, Intracystic hemorrhage, Cerebrospinal fluid

\section{Abbreviations \\ AC: Arachnoid Cyst; CPA: Cerebellopontine Angle; CSF: Cerebrospinal Fluid}

\section{Introduction}

Arachnoid cysts (AC) are common findings on neuroimaging and account for approximately $1 \%$ of all intracranial lesions. They are developmental collections of cerebrospinal fluid (CSF) enveloped by an arachnoid membrane contiguous with the subarachnoid space. These lesions most commonly occur within the middle cranial fossa, with the cerebellopontine angle (CPA) being the second most common location, accounting for approximately $5.2 \%$ of all AC $[1,2]$. The majority of
AC are asymptomatic with a benign natural history; however, they can become symptomatic. This is thought to be due to cyst growth and mass effect on adjacent neurovascular structures, or rarely, after cyst rupture with a combination of intracystic and/or extraaxial intracranial hemorrhage. AC hemorrhage has been reported at rates of $2.3-4.6 \%$ however these rates are likely overreported as there is a likely underreported prevalence of all AC as so many are undiagnosed and asymptomatic [3]. Symptomatic AC are commonly treated with surgical resection, with or without shunting. To our knowledge, we present the first report of a CPA $\mathrm{AC}$ with spontaneous intracystic hemorrhage in an adult successfully managed conservatively, along with review of the literature.

\section{Case Report}

A 40-year-old male presented with acute onset headache and neck pain which began three days prior to presentation. Due to a progressively worsening headache, along with nausea and vomiting, he presented to our emergency department. The patient had untreated hypertension and was noted to have a presenting blood pressure of 231/133. Physical examination revealed intact neurological function. Computed tomography (CT) of the head was performed and demonstrated a $3.3 \times 1.8 \mathrm{~cm}$ extra-axial homogeneously hyperdense mass in the left CPA causing regional mass effect on the brainstem and nearby neurovascular structures, with mild dilation of the third and fourth ventricles (Figure 1). MRI of the brain demonstrated a well-circumscribed

Citation: Passer J, Kaul A, Almefty RO (2021) Spontaneous Intracystic Hemorrhage in an Adult with Cerebellopontine Angle Arachnoid Cyst and Management: A Case Report. Neurosurg Cases Rev 4:070. doi.org/10.23937/2643-4474/1710070

Accepted: June 22, 2021; Published: June 24, 2021

Copyright: (C) 2021 Passer J, et al. This is an open-access article distributed under the terms of the Creative Commons Attribution License, which permits unrestricted use, distribution, and reproduction in any medium, provided the original author and source are credited. 

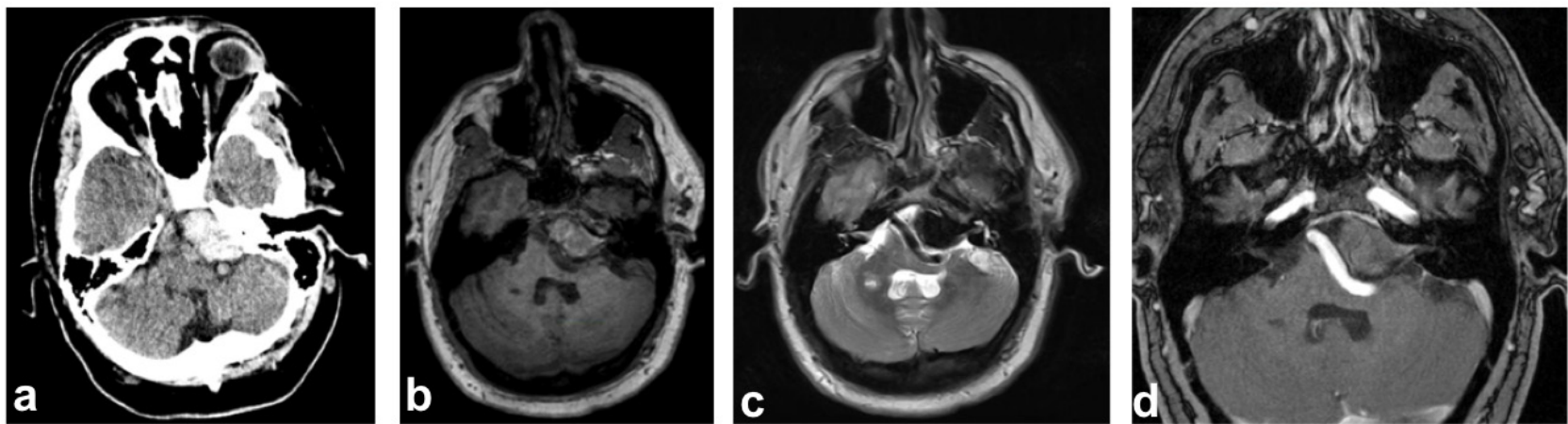

Figure 1: Cerebellopontine angle arachnoid cyst with intracystic hemorrhage. Non-contrast CT. a) Of the head demonstrating a $3.3 \times 1.8 \mathrm{~cm}$ hyperdense lesion in the left cerebellopontine angle. Axial MRI images with T1 non contrast isointensity; b) T2 hypointensity; c) T1 post gadolinium contrast with minimal enhancement; d) Showing a left cerebellopontine mass which appears to arise from the posterior petrous temporal bone with extension into the left internal auditory canal.
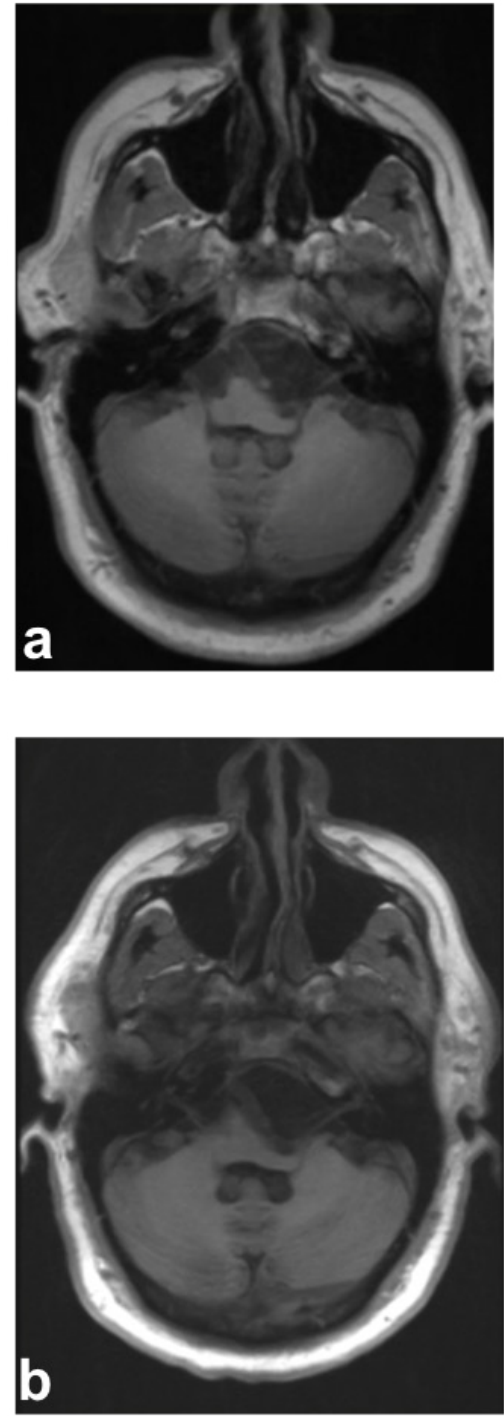
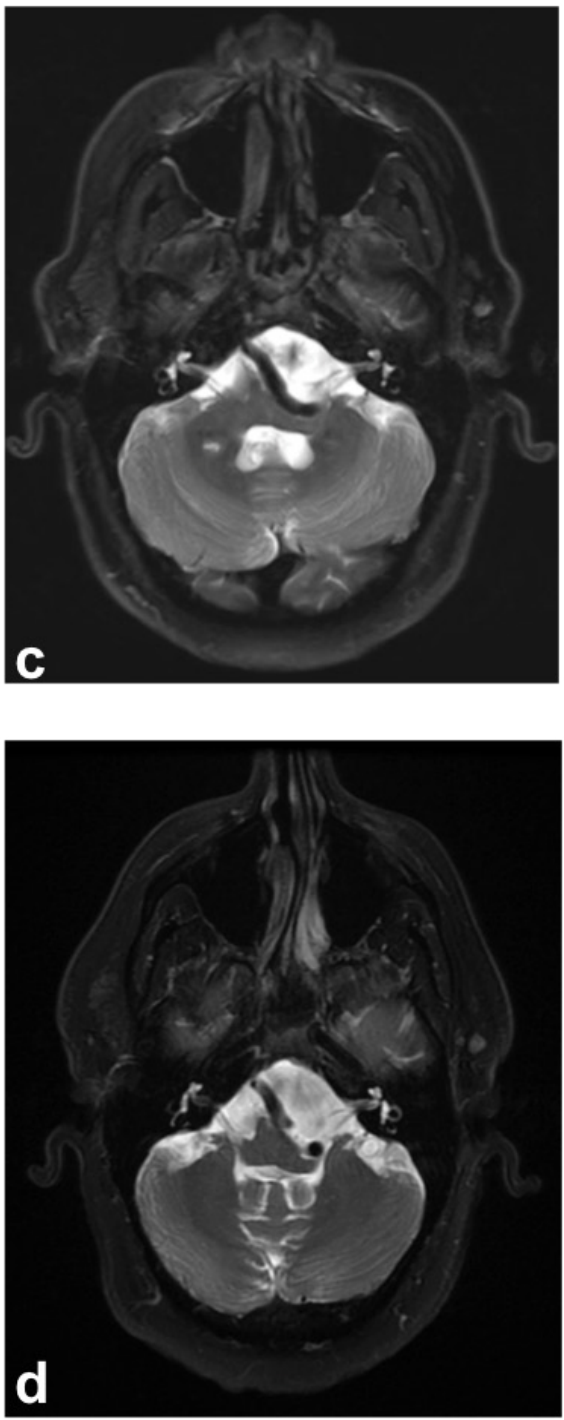

Figure 2: Resolution of intracystic hemorrhage at 8 weeks (top row) and 6 months (bottom row) after presentation. a,b) Axial MRI images with T1 non contrast; c,d) T2 weighted; e,f) T1-post gadolinium; a,c,e) Showing a left CPA mass with complete resolution of intracystic hemorrhage at 8 weeks; b,d,f) 6 months. Note the T1-hypointense/T2-hyperintense signal within the extra axial cyst that is consistent with CSF signal and resolution of hemorrhage within a CPA arachnoid cyst.

T1 isointense, T2 hypointense, faint homogeneously gadolinium enhancing, extra-axial mass which appeared to be arising from the left petrous temporal bone with extension into the internal auditory canal. There was a focal area of T1 hyperintensity interpreted as calcification. Imaging characteristics of the lesion were 
thought to be most consistent with a meningioma with intratumoral hemorrhage. Additionally, T2 hyperintensities in the white matter were present, consistent with a history of uncontrolled hypertension. Conventional diagnostic angiography was negative for tumor blush or underlying vascular malformation.

The patient continued to experience brittle hypertension despite continuous IV medication which delayed our initial planned surgical intervention of a retrosigmoid craniotomy and resection of the mass. He eventually required four oral anti-hypertensive medications at high doses in order to control his blood pressure. In light of his intact neurological examination, as well as difficulty with medical optimization of his uncontrolled hypertension, the decision was made to pursue resection on an elective basis as an outpatient once he was maintained on a stable medication regimen. He was discharged from the hospital without issue. He underwent a repeat MRI of the brain approximately 8 weeks later. The repeat MRI demonstrated complete resolution of hemorrhage and gadolinium enhancement (Figure 2). All that remained was a T2 hyperintense signal most consistent with a left CPA arachnoid cyst. His headaches had resolved at this time. Six month follow up MRI showed stable size and morphology of the CPA AC indicating successful durability and safety conservative observation alone.

\section{Discussion}

Arachnoid cysts of the cerebellopontine angle are uncommon with a prevalence of $5.2 \%$ [1]. Most typically, CPA arachnoid cysts are incidental findings in asymptomatic patients and can be safely monitored with serial imaging. Patients with symptomatic CPA AC can present with a variety of symptoms due to brainstem or cranial nerve compression [2] including sensorineural hearing loss [4,5] diplopia [6], trigeminal neuralgia [7], vertigo [8], hemifacial spasm [9], facial paresis [10], glossopharyngeal neuralgia [11], hoarseness and dysphagia [12]. Jallo, et al. reviewed 33 cases of CPA $A C$ and discussed optimal surgical management. The authors stated that $A C$ which demonstrate progression in regard to size, symptoms of neural compression, hydrocephalus or refractory headaches/emesis require surgical intervention. They recommend suboccipital craniotomy and cyst fenestration [2]. There has not been a discussion in the literature regarding conservative management of spontaneous intracystic hemorrhage in CPA AC.

Intracystic hemorrhage is a rare complication of arachnoid cysts. There are several cases in the literature of patients with supratentorial arachnoid cysts who present with simultaneous subdural hematoma in addition to intracystic hemorrhage. In this scenario, intracystic hemorrhage can be masked on initial radiological examination secondary to the presence of an extra-axial hematoma which occurs secondary to extravasation of blood into the subdural or epidural space [3,13-15]. Only two reported cases of intracavitary hemorrhage in an infratentorial arachnoid cyst have been reported $[16,17]$. Both cases involved a retroclival arachnoid cyst. In both instances, hemorrhage was thought to be spontaneous as is true in our presented case. The patients both underwent suboccipital craniotomies (Table 1).

Isolated intracystic hemorrhage, without associated subdural or subarachnoid hemorrhage, is a rare complication. The exact pathophysiologic mechanism behind intracystic rupture is not clearly defined, but several mechanisms have been proposed [13]. Reported cases have occurred both spontaneously as well as in the setting of trauma. Cress, et al. reviewed 14 pediatric cases of patients with intracystic AC hemorrhage with or without concurrent extra-axial collection and noted that larger size of $\mathrm{AC}(>5 \mathrm{~cm})$ and recent history of head trauma (including minor head trauma) within prior 30 days were significantly associated with AC rupture [3]. The authors purported that unrecognized trauma can cause flow changes within CSF, which become magnified within an AC. As arachnoid cysts are less compliant than the surrounding subarachnoid CSF spaces, this phenomenon can lead to rupture of vessels within the cyst wall or by bridging veins, resulting in intracystic or subdural hemorrhage, respectively [15].

However, our adult patient presented with spontaneous posterior fossa intracystic hemorrhage in the setting of profound hypertension and denied any history of trauma. In this scenario, other mechanisms of hemorrhage could be more likely. Previous microscopic

Table 1: Published studies of adults with spontaneous intracystic posterior fossa AC hemorrhage.

\begin{tabular}{|l|l|l|l|l|l|}
\hline Study & Year & $\begin{array}{l}\text { Number of } \\
\text { patients }\end{array}$ & Age/Sex/Symptoms & Intervention & Outcome \\
\hline Akyuz, et al. [16] & 2010 & $\mathrm{~N}=1$ & $\begin{array}{l}40 / \text { F/Occipito-cervical } \\
\text { pain, emesis }\end{array}$ & $\begin{array}{l}\text { Right far-lateral } \\
\text { suboccipital } \\
\text { craniotomy }\end{array}$ & Not Described \\
\hline Ikeda, et al. [17] & 2000 & $\mathrm{~N}=1$ & $\begin{array}{l}57 / \text { M/Diplopia (right CN } \\
\text { VI palsy) }\end{array}$ & $\begin{array}{l}\text { Right lateral } \\
\text { Suboccipital } \\
\text { craniotomy }\end{array}$ & Not Described \\
\hline Current Study & 2020 & $\mathrm{~N}=1$ & $\begin{array}{l}\text { 40/ M/Headaches, } \\
\text { emesis }\end{array}$ & $\begin{array}{l}\text { Conservative } \\
\text { management }\end{array}$ & Neurologically intact \\
\hline
\end{tabular}


analyses of $A C$ walls have shown a mesothelial cell layer in close proximity with bridging veins. Differences in osmotic gradient between subarachnoid and intracystic fluid, fluid entrapment due to a slit-valve mechanism, as well as independent fluid production by these mesothelial cells lining cyst walls may explain spontaneous cyst enlargement [18]. If a sufficient intracystic pressure is attained to breach the wall, the surrounding vasculature could be interrupted [19]. Recurrent episodes of this disruption of friable blood vessels within the cyst wall is thought to be a potential source of microhemorrhage within AC. Recurrent microhemorrhages or a large intracystic hemorrhage can cause an increase in size of the AC over time which can eventually cause rupture of the cyst into the subarachnoid and even subdural space [14].

Specifically, in our patient, we propose that his chronic untreated hypertension may have further exacerbated the risk of hemorrhage from these already vulnerable vessels through mechanisms similar to those which have previously been well-described in hypertensive intracerebral hemorrhage. In this model, chronic microvascular changes such as progressive hypertrophy of the tunica media within the wall of the arteriole lead to a progressive hypoxic degeneration and fibrinoid necrosis of the smooth muscle layer. This process leads to collagen deposition and results in a weakening of the arteriolar wall. In some cases, amyloid proteins can deposit in the vessel wall, whereas others develop Charcot-Bouchard aneurysmal dilatations in these vessel walls. These are the likely points of rupture in the setting of elevated systolic blood pressures [20].

\section{Conclusion}

Cerebellopontine angle arachnoid cysts are rare intracranial lesions. Pure intracystic hemorrhage within these lesions is even more rare. Patients who present with symptomatic lesions with associated subdural hematoma or with neurological deterioration should be considered for emergent decompression and cyst fenestration. However, in the setting of acute intracystic hemorrhage in an individual who is neurologically intact we propose conservative management. Medical management of risk factors for hypertensive hemorrhages should be targeted in individuals with nontraumatic spontaneous intracystic hemorrhage. We caution that the presence of a well-circumscribed, spontaneous extra-axial, posterior fossa hemorrhage should raise suspicion for an underlying AC.

\section{Ethical Approval}

All procedures performed in studies involving human participants were in accordance with the ethical standards of the institutional and/or national research committee and with the 1964 Helsinki declaration and its later amendments or comparable ethical standards. This article does not contain any studies with human participants or animals performed by any of the authors.

\section{Informed Consent}

For this type of study formal consent is not required. No identifiable information was included in this manuscript.

\section{Conflict of Interest}

All authors certify that they have no affiliations with or involvement in any organization or entity with any financial interest (such as honoraria; educational grants; participation in speakers' bureaus; membership, employment, consultancies, stock ownership, or other equity interest; and expert testimony or patentlicensing arrangements), or non-financial interest (such as personal or professional relationships, affiliations, knowledge or beliefs) in the subject matter or materials discussed in this manuscript.

\section{Funding Sources}

No funding was received for this research.

\section{Author Contributions}

All authors contributed substantially to the conception or design of the work. JP and AK and ROA responsible for critical revision for important intellectual content and the final approval to be published. All authors agree to be accountable for all aspects of the work in ensuring that questions related to the accuracy or integrity of any part of the work are appropriately investigated and resolved.

\section{References}

1. Helland CA, Lund-Johansen M, Wester K (2010) Location, sidedness, and sex distribution of intracranial arachnoid cysts in a population-based sample. J Neurosurg 113: 934939.

2. Jallo GI, Woo HH, Meshki C, Epstein FJ, Wisoff JH (1997) Arachnoid cysts of the cerebellopontine angle: Diagnosis and surgery. Neurosurgery 40: 31-37.

3. Cress M, Kestle JR, Holubkov R, Riva-Cambrin J (2013) Risk factors for pediatric arachnoid cyst rupture/hemorrhage: A case-control study. Neurosurgery 72: 716-722.

4. Cavusoglu H, Kahyaoglu O, Aydin Y (2015) Arachnoid cyst of the cerebellopontine angle causing isolated acute hearing loss, with literature review. Acta Neurochir (Wien) 157: 1999-2001.

5. Giordano M, Gallieni M, Samii A, Di Rocco C, Samii M (2018) Surgical management of cerebellopontine angle arachnoid cysts associated with hearing deficit in pediatric patients. J Neurosurg Pediatr 21: 119-123.

6. Eslick GD, Chalasani V, Seex K (2002) Diplopia and headaches associated with cerebellopontine angle arachnoid cyst. ANZ J Surg 72: 915-917.

7. Grande-Martin A, Diaz-Conejo R, Verdu-Perez A, Hernandez-Moneo JL (2015) Trigeminal neuralgia in a child with a cerebellopontine angle arachnoid cyst. Pediatr Neurol 53: 178-179.

8. Tunes C, Flones I, Helland C, Goplen F, Wester KG (2015) 
Disequilibrium in patients with posterior fossa arachnoid cysts. Acta Neurol Scand 132: 23-30.

9. Mastronardi L, Taniguchi R, Caroli M, Crispo F, Ferrante L, et al. (2009) Cerebellopontine angle arachnoid cyst: A case of hemifacial spasm caused by an organic lesion other than neurovascular compression: Case report. Neurosurgery 65: E1205.

10. Gonul E, Izci Y, Onguru O (2007) Arachnoid cyst of the cerebellopontine angle associated with gliosis of the eighth cranial nerve. J Clin Neurosci 14: 700-702.

11. Cho TG, Nam TK, Park SW, Hwang SN (2011) Glossopharyngeal neuralgia caused by arachnoid cyst in the cerebellopontine angle. J Korean Neurosurg Soc 49: 284-286.

12. Hayden MG, Tornabene SV, Nguyen A, Thekdi A, Alksne JF (2007) Cerebellopontine angle cyst compressing the vagus nerve: Case report. Neurosurgery 60: E1150.

13. Adin ME, Yildiz MS, Deniz MA, Behzadi AH, Mata-Mbemba D (2018) Arachnoid cysts with spontaneous intracystic hemorrhage and associated subdural hematoma: Report of management and follow-up of 2 cases. Radiol Case Rep 13: $516-521$.
14. laconetta G, Esposito M, Maiuri F, Cappabianca P (2006) Arachnoid cyst with intracystic haemorrhage and subdural haematoma: Case report and literature review. Neurol Sci 26: 451-455.

15. Page A, Paxton RM, Mohan D (1987) A reappraisal of the relationship between arachnoid cysts of the middle fossa and chronic subdural haematoma. J Neurol Neurosurg Psychiatry 50: 1001-1007.

16. Akyuz M, Goksu E, Aralasmak A, Tuncer R (2010) Retroclival arachnoid cyst presenting with haemorrhage: A brief report of a special case. Acta Neurochir (Wien) 152: 161-162.

17. Ikeda H, Deinsberger W, Boker DK (2000) Retroclival arachnoid cyst presenting with spontaneous intracystic haemorrhage--case presentation. Acta Neurochir (Wien) 142: 1317-1318.

18. Starkman SP, Brown TC, Linell EA (1958) Cerebral arachnoid cysts. J Neuropathol Exp Neurol 17: 484-500.

19. Huang D, Abe T, Kojima K, Tanaka N, Watauabe M, et al. (1999) Intracystic hemorrhage of the middle fossa arachnoid cyst and subdural hematoma caused by ruptured middle cerebral artery aneurysm. AJNR Am J Neuroradiol 20: 1284-1286.

20. Sutherland GR, Auer RN (2006) Primary intracerebral hemorrhage. J Clin Neurosci 13: 511-517. 